\title{
Geodermatophilus poikilotrophi sp. nov.: A Multitolerant Actinomycete Isolated from Dolomitic Marble
}

\author{
Maria del Carmen Montero-Calasanz, ${ }^{1,2}$ Benjamin Hofner, ${ }^{3}$ \\ Markus Göker, ${ }^{1}$ Manfred Rohde, ${ }^{4}$ Cathrin Spröer, ${ }^{1}$ Karima Hezbri, ${ }^{5}$ \\ Maher Gtari, ${ }^{5}$ Peter Schumann, ${ }^{1}$ and Hans-Peter Klenk ${ }^{1}$ \\ ${ }^{1}$ Leibniz Institute DSMZ-German Collection of Microorganisms and Cell Cultures, Inhoffenstraße 7B, 38124 Braunschweig, Germany \\ ${ }^{2}$ Instituto de Investigacióon y Formacióon Agraria y Pesquera (IFAPA), Centro Las Torres-Tomejil, \\ Carretera Sevilla-Cazalla de la Sierra, Km 12.2, 41200 Alcalá del Río, Sevilla, Spain \\ ${ }^{3}$ Institut für Medizininformatik, Biometrie und Epidemiologie, Friedrich-Alexander-Universität Erlangen-Nürnberg, \\ Waldstraße 6, 91054 Erlangen, Germany \\ ${ }^{4}$ Helmholtz Centre for Infection Research (HZI), Inhoffenstraße 7, 38124 Braunschweig, Germany \\ ${ }^{5}$ Laboratoire Microorganismes et Biomolécules Actives, Université de Tunis Elmanar (FST) et Université de Carthage (INSAT), \\ 2092 Tunis, Tunisia
}

Correspondence should be addressed to Maria del Carmen Montero-Calasanz; maria.montero-calasanz@dsmz.de and Hans-Peter Klenk; hpk@dsmz.de

Received 1 April 2014; Revised 3 June 2014; Accepted 9 June 2014; Published 9 July 2014

Academic Editor: Sara Borin

Copyright (C) 2014 Maria del Carmen Montero-Calasanz et al. This is an open access article distributed under the Creative Commons Attribution License, which permits unrestricted use, distribution, and reproduction in any medium, provided the original work is properly cited.

\begin{abstract}
A novel Gram-reaction-positive, aerobic actinobacterium, tolerant to mitomycin C, heavy metals, metalloids, hydrogen peroxide, desiccation, and ionizing- and UV-radiation, designated $\mathrm{G} 18^{\mathrm{T}}$, was isolated from dolomitic marble collected from outcrops in Samara (Namibia). The growth range was $15-35^{\circ} \mathrm{C}$, at $\mathrm{pH} 5.5-9.5$ and in presence of $1 \% \mathrm{NaCl}$, forming greenish-black coloured colonies on GYM Streptomyces agar. Chemotaxonomic and molecular characteristics of the isolate matched those described for other representatives of the genus Geodermatophilus. The peptidoglycan contained meso-diaminopimelic acid as diagnostic diaminoacid. The main phospholipids were phosphatidylethanolamine, phosphatidylcholine, phosphatidylinositol, and small amount of diphosphatidylglycerol. MK-9 $\left(\mathrm{H}_{4}\right)$ was the dominant menaquinone and galactose was detected as diagnostic sugar. The major cellular fatty acids were branched-chain saturated acids iso- $\mathrm{C}_{16: 0}$ and iso- $\mathrm{C}_{15: 0}$ and the unsaturated $\mathrm{C}_{17: 1} \omega 8 \mathrm{c}$ and $\mathrm{C}_{16: 1} \omega 7 \mathrm{c}$. The 16S rRNA gene showed 97.4-99.1\% sequence identity with the other representatives of genus Geodermatophilus. Based on phenotypic results and 16S rRNA gene sequence analysis, strain $\mathrm{G}^{\mathrm{T}}{ }^{\mathrm{T}}$ is proposed to represent a novel species, Geodermatophilus poikilotrophi. Type strain is G18 ${ }^{\mathrm{T}}\left(=\mathrm{DSM} 44209^{\mathrm{T}}=\right.$ CCUG $\left.63018^{\mathrm{T}}\right)$. The INSDC accession number is HF970583. The novel R software package lethal was used to compute the lethal doses with confidence intervals resulting from tolerance experiments.
\end{abstract}

\section{Introduction}

The family cursive was originally proposed by Normand et al. [1], but a formal description of the family name was only published a decade later [2]. At the time of writing, the family comprises the genera Blastococcus, Modestobacter, and Geodermatophilus (as the type genus). Geodermatophilus was proposed by Luedemann [3] and was included in the Approved Lists of Bacterial Names [4]. This genus was poorly studied for a long time due to difficulties in culturing isolates [5], in spite of the fact that its members are frequently isolated from arid soils [5] and occasionally from arid and semiarid rock substrates such as rock vanish and marble $[6,7]$, where a variety of environmental changing factors influence their settlement, growth, and development [8]. Some of them were also isolated from rhizosphere soil $[9,10]$. To enable the survival in such extreme ecological niches, where bacterial cells are suppressed to reactive oxygen species 
(ROS) generating-stresses, those should exhibit a very broad range of tolerance to multiple and fluctuating environmental stresses, such as solar radiation, desiccation and rehydration, temperature fluctuations, salts, and metals [8, 11], and a probable ionizing-radiation (IR) resistance. The origin of this last capability cannot be explained as adaptation to environment, suggesting an "incidental" result of tolerance to desiccation, whose DNA damage pattern is similar to that generated by ionizing radiation in Deinococcus species [12]. Furthermore, tolerance to hydrogen peroxide and mitomycin $\mathrm{C}$ as indicators of the presence of an efficient microbial oxidative stress repair and double-strand break repair system, characteristics also attributed to radiation resistance, have been widely studied $[13,14]$. Multiple-stress tolerance of the type strain Geodermatophilus obscurus was already described by Gtari et al. [11], suggesting a correlation between tolerance profiles to desiccation, mitomycin $\mathrm{C}$, hydrogen peroxide, and ionizing- and UV-radiation. Previous works of Rainey et al. [15] and Giongo et al. [16] already revealed the prevalence of IR resistant Geodermatophilus isolates from arid soil sample at comparatively the same radiation levels as observed for Deinococcus species and the predominance of species belongs to the family Geodermatophilaceae detected from intercontinental dust, illustrating, therefore, to resist radiation and desiccation stresses during travel in the high atmosphere.

Fourteen named species have been classified in the genus Geodermatophilus (ordered by the dates of effective publication of the names): G. obscurus [3], G. ruber [9], G. nigrescens [17], G. arenarius [18], G. siccatus [19, 20], G. saharensis [20, 21], G. tzadiensis [22, 23], G. telluris [24], G. soli and G. terrae [10], G. africanus [5, 23], G. normandii [25], G. taihuensis [26], and G. amargosae [27, 28]. Until now, only the genome of the type strain of the type species, $G$. obscurus $\mathrm{G}-20^{\mathrm{T}}$, has been sequenced [29]. Moreover, three subspecies have been identified and named, but their names were not validly published yet: "G. obscurus subsp. utahensis," "G. obscurus subsp. dictyosporus" [3], and "G. obscurus subsp. everesti" $[30,31]$. This study describes the taxonomic position of a novel species into the genus Geodermatophilus based on a polyphasic approach and its tolerance to different environmental stresses.

\section{Materials and Methods}

2.1. Isolation. During screening for microorganisms from dolomitic marble outcrops in an agriculture area at 1150 masl in Samara, near to Namib desert (Namibia), a greenish-black strain designated as $\mathrm{G} 18^{\mathrm{T}}$ was isolated (in 1993) and purified as described by Eppard et al. [7].

\subsection{Morphological and Biochemical Characterization. Cul-} tural characteristics were tested on GYM Streptomyces medium (DSMZ medium 65), TSB agar (DSMZ medium 535), GPHF medium (DSMZ medium 553), R2A medium (DSMZ medium 830), GEO medium (DSMZ medium 714), PYGV medium (DSMZ medium 621), and Luedemann medium (DSMZ medium 877) for 15 days at $28^{\circ} \mathrm{C}$. To determine its morphological characteristics, strain $\mathrm{G} 18^{\mathrm{T}}$ was cultivated on GYM Streptomyces medium at $28^{\circ} \mathrm{C}$. Colony features were observed at 4 and 15 days under a binocular microscope according to Pelczar Jr. [32]. Exponentially growing bacterial cultures were observed with an optical microscope (Zeiss AxioScope A1) with a 100-fold magnification and phase-contrast illumination. Micrographs of bacterial cells grown on GYM Streptomyces broth after 7 days were taken with a field-emission scanning electron microscope (FE-SEM Merlin, Zeiss, Germany). Gram reaction was performed using the $\mathrm{KOH}$ test described by Gregersen [33]. Cell motility was observed on modified ISP2 [34] swarming agar $(0.3 \%, \mathrm{w} / \mathrm{v})$ at $\mathrm{pH} 7.2$ supplemented with $\left(\mathrm{l}^{-1}\right) 4.0 \mathrm{~g}$ dextrin, $4.0 \mathrm{~g}$ yeast extract, and $10.0 \mathrm{~g}$ malt extract. Oxidase activity was analysed using filter-paper disks (Sartorius grade 388) impregnated with $1 \%$ solution of $N, N, N^{\prime}, N^{\prime}$-tetramethylp-phenylenediamine (Sigma-Aldrich); a positive test was defined by the development of a blue-purple colour after applying biomass to the filter paper. Catalase activity was determined based on formation of bubbles following the addition of 1 drop of $3 \% \mathrm{H}_{2} \mathrm{O}_{2}$. Growth rates were determined on plates of GYM Streptomyces medium for temperatures from 10 to $50^{\circ} \mathrm{C}$ at $5^{\circ} \mathrm{C}$ increments and for $\mathrm{pH}$ values from 4.0 to 12.5 (in increments of $0.5 \mathrm{pH}$ units) on modified ISP 2 medium by adding $\mathrm{NaOH}$ or $\mathrm{HCl}$, respectively, since the use of a buffer system inhibited growth of the strains. The utilization of carbon compounds and acid production were tested at $28^{\circ} \mathrm{C}$ using API $20 \mathrm{NE}$ strips (bioMérieux) and GEN III Microplates in an Omnilog device (BIOLOG Inc., Hayward, CA, USA) in comparison with the reference strains G. africanus DSM 45422 ${ }^{\mathrm{T}}$, G. amargosae DSM $46136^{\mathrm{T}}$, G. arenarius DSM $45418^{\mathrm{T}}$, G. nigrescens DSM $45408^{\mathrm{T}}, G$. normandii DSM $45417^{\mathrm{T}}$, G. obscurus DSM $43160^{\mathrm{T}}$, G. ruber DSM $45317^{\mathrm{T}}$, G. saharensis DSM $45423^{\mathrm{T}}$, G. siccatus DSM $45419^{\mathrm{T}}$, G. soli DSM $45843^{\mathrm{T}}$, G. taihuensis DSM $45962^{\mathrm{T}}, \mathrm{G}$. telluris DSM $45421^{\mathrm{T}}$, G. terrae DSM $45844^{\mathrm{T}}$, and G. tzadiensis DSM $45416^{T}$ in parallel assays. The GEN III Microplates were inoculated with cells suspended in a viscous inoculating fluid (IF C) provided by the manufacturer at a cell density of $70 \%$ transmittance (T) for G. amargosae DSM $46136^{\mathrm{T}}$, at $75-79 \%$ $\mathrm{T}$ for G. africanus DSM $45422^{\mathrm{T}}$, at $90 \% \mathrm{~T}$ for G. arenarius DSM $45418^{\mathrm{T}}$ and G. taihuensis DSM $45962^{\mathrm{T}}$, and at $80-83 \% \mathrm{~T}$ for all other reference strains. Respiration rates (and growth) were measured yielding a total running time of 5 or 10 days, depending on the strain, in phenotype microarray mode. Each strain was studied in two independent repetitions. Data were exported and analysed using the opm package for $\mathrm{R}$ $[35,36]$ v.1.0.6. Reactions with a distinct behaviour between the two repetitions were regarded as ambiguous. Clustering analyses of the phenotypic microarrays were constructed using the pvclust package for R v.1.2.2. [37]. Enzymatic activities were tested using API ZYM galleries according to the instructions of the manufacturer (bioMérieux). Chemotaxonomic procedures. Whole-cell sugars were prepared according to Lechevalier and Lechevalier [38], followed by thin layer chromatography (TLC) analysis [39]. Polar lipids were extracted, separated by two-dimensional TLC, and identified according to procedures outlined by Minnikin et al. [40] with modifications proposed by Kroppenstedt and 
Goodfellow [41]. Additionally, choline-containing lipids were detected by spraying with Dragendorff's reagent (Merck) [42]. Menaquinones (MK) were extracted from freeze-dried cell material using methanol as described by Collins et al. [43] and analysed by high-performance liquid chromatography (HPLC) [44]. The extraction and analysis of cellular fatty acids were carried out in two independent repetitions from biomass grown on GYM agar plates held at $28^{\circ} \mathrm{C}$ for 4 days and harvested always from the same sector (the last quadrant streak). Analysis was conducted using the microbial identification system (MIDI) Sherlock Version 4.5 (method TSBA40, ACTIN6 database) as described by Sasser [45]. The annotation of the fatty acids in the ACTIN6 peak naming table is consistent with IUPAC nomenclature (i.e., double bond positions identified with reference to the carboxyl group of the fatty acid), but for consistency with other publications this has been altered to numbering from the aliphatic end of the molecule (i.e., 16:1 CIS 9 become 16:1 $\omega 7 \mathrm{c}$, etc.). The composition of peptidoglycan hydrolysates (6 $\mathrm{N} \mathrm{HCl}, 100^{\circ} \mathrm{C}$ for $16 \mathrm{~h}$ ) was examined by TLC as described by Schleifer and Kandler [46]. All chemotaxonomical analyses were conducted under standardized conditions with strain $\mathrm{G} 8^{\mathrm{T}}$ and cultures of the same set of reference strains as listed above for morphological and biochemical characterisations.

\subsection{Genetic and Phylogenetic Analysis. G $+\mathrm{C}$ content of} chromosomal DNA of strain $\mathrm{G} 18^{\mathrm{T}}$ was determined by HPLC according to Mesbah et al. [47]. Genomic DNA extraction, PCR-mediated amplification of the 16S rRNA gene, and purification of the PCR product were carried out as described by Rainey et al. [48]. Phylogenetic analysis was based on an alignment of $16 \mathrm{~S}$ rRNA gene sequences from type strains of all species with effectively published names in the Geodermatophilaceae inferred as described by Montero-Calasanz et al. [5]. Pairwise similarities were calculated as recommended by Meier-Kolthoff et al. [49]. For DNA-DNA hybridization tests, cells were disrupted by using a Constant Systems TS $0.75 \mathrm{KW}$ (IUL Instruments, Germany). DNA in the crude lysate was purified by chromatography on hydroxyapatite as described by Cashion et al. [50]. DNA-DNA hybridization was carried out as described by De Ley et al. [51] under consideration of the modifications described by Huss et al. [52] using a model Cary 100 Bio UV/VIS-spectrophotometer equipped with a Peltier-thermostatted $6 \times 6$ multicell changer and a temperature controller with in situ temperature probe (Varian).

2.4. Tolerance Experiments. The tolerance of strain $\mathrm{G} 18^{\mathrm{T}}$ and G. obscurus $\mathrm{G}-20^{\mathrm{T}}$ (DSM 43160), as a positive control [11], to ionizing- and UV-radiation, mitomycin C, hydrogen peroxide, desiccation, and heavy metals/metalloids, was assayed using nonsporulating cultures obtained by growth in TYB medium [53] at $28^{\circ} \mathrm{C}$ for 5 days, washed twice with $0.9 \% \mathrm{NaCl}$, homogenized, and subsequently resuspended in saline solution. Ionizing-radiation experiments were carried out according to a protocol outlined by Gtari et al. [11]. To test the resistance to UV-radiation, $0.5 \mathrm{~mL}$ aliquots of culture suspensions was spread onto GYM Streptomyces agar plates in duplicate in two independent experiments and then exposed to a dose of 5-10 J.s $\mathrm{s}^{-1} \mathrm{~m}^{-2}$ in a laminar flow hood equipped with crossbeam $254 \mathrm{~nm}$ UV sources in both side walls (Safe 2020, Thermo Scientific) for 1, 10, 30, 60, 120, 240, and $600 \mathrm{~min}$. After 2 weeks at $28^{\circ} \mathrm{C}$, the survival fractions were calculated based on the c.f.u. $\mathrm{mL}^{-1}$. The UV shadow zone was avoided. The tolerance to DNA damaging agent mitomycin $\mathrm{C}$ was tested in two independent experiments by incubation of cell suspension at room temperature with the antibiotic at a final concentration of $5 \mu \mathrm{g} \cdot \mathrm{mL}^{-1}$. After $1,5,10,20,40,60$, and $120 \mathrm{~min}$, samples were centrifuged at $3500 \mathrm{rpm}$ for $4 \mathrm{~min}$, washed twice in $0.9 \% \mathrm{NaCl}$, and, subsequently, serially diluted. Aliquots were spread on GYM Streptomyces agar in duplicate. After incubation, the survival fractions were calculated based on the c.f.u. $\mathrm{mL}^{-1}$. To test the resistance to hydrogen peroxide, equal volumes of cell suspensions and $0.5 \%$ hydrogen peroxide were incubated at room temperature in two independent experiments. After 1, $5,10,20,40,60$, and $120 \mathrm{~min}$, samples were handled as was previously described in mitomycin experiments to calculate the survival fractions. For desiccation tolerance, $25 \mu \mathrm{L}$ of cell suspension were transferred to individual wells of microtiter plates in triplicate. Unsealed microtiter plates were placed in a desiccator (23.5\% relative humidity) containing silica gel rubin (Fluka) at room temperature. After 20, 40, 60, 80, and 100 days, $250 \mu \mathrm{L}$ of sterile water was added to individual wells to rehydrate the desiccated cells and then incubated at room temperature for 1 hour and plated on GYM Streptomyces agar. The determination of survival fractions was conducted as described above. The sensitivity of strain $\mathrm{G} 18^{\mathrm{T}}$ to heavy metals and metalloids was determined by a growth inhibition plate assay as described by Richards et al. [54]. $\mathrm{AgNO}_{3}$, $\mathrm{CuCl}_{2}, \mathrm{CoCl}_{2}, \mathrm{NiCl}_{2}, \mathrm{~K}_{2} \mathrm{CrO}_{4}, \mathrm{~Pb}\left(\mathrm{NO}_{3}\right)_{2}$, and $\mathrm{Na}_{2} \mathrm{HAsO}_{4}$ were added to GYM Streptomyces medium at 0.1, 0.3, 0.5, 1.0, $2.0,4.0,8.0,10.0,30.0$, and $50.0 \mathrm{mM}$. Growth was evaluated after 1 month at $28^{\circ} \mathrm{C}$, determining minimum inhibitory concentration (MIC).

2.5. Statistical Analysis of Tolerance Experiments. To evaluate the tolerance of strain G18 ${ }^{\mathrm{T}}$ and G. obscurus DSM $43160^{\mathrm{T}}$ with respect to the various physiological challenges, the median lethal dose (LD50) and the lethal dose 10 (LD10) values were computed for both strains. As the number of bacteria initially used in each experiment cannot directly be obtained and consequently, death rates or survival rates cannot be directly computed; standard models based on logistic regression models to obtain LD values are thus not available. A negative binomial model for count data [55] was used to estimate of number of survivors dependent on dose, strain, and experiment. Penalized splines [56], one for each strain, were used to allow the dose to have a nonlinear influence on survival fractions. The estimation process was stabilised by using of a square root transformation on dose. LD50 and LD10 values were subsequently estimated from the model and 95\% confidence intervals were obtained using a parametric bootstrap approach [57, Chapter 5.4]. Details on model fitting and the estimation of the confidence intervals as well as code to derive LD values from survival count 


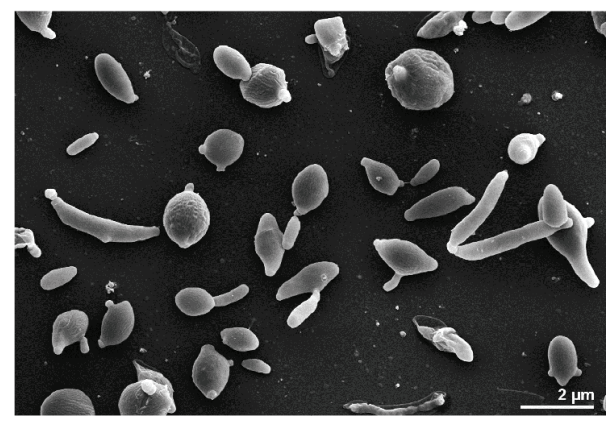

FIGURE 1: Scanning electron micrograph of strain $\mathrm{G} 18^{\mathrm{T}}$ grown on GYM Streptomyces medium for 7 days at $28^{\circ} \mathrm{C}$.

data with one or two strains can be found in the supplementary material (see Figure S4 in Supplementary Material available online at http://dx.doi.org/10.1155/2014/914767). All computations were done with $\mathrm{R}[58]$ using the $\mathrm{R}$ software packages mgcv [57] and lethal [59].

\section{Results and Discussion}

3.1. Morphological and Biochemical Characteristics. Cells of strain $\mathrm{G} 18^{\mathrm{T}}$ were pleiomorphic and Gram-reaction-positive. Individual cells and aggregates were observed, confirming reports by Ishiguro and Wolfe [53] of synchronous morphogenesis on unspecific media and previous observations on other representatives of the genus Geodermatophilus [27]. In line with the original description by Luedemann [3], circular or elliptical motile zoospores and septated filaments from zoospore germination were observed (Figure 1). Young colonies were light-red in colour and turned greenish-black at maturity. Similar colours conversions were already observed by Nie et al. [17] and Montero-Calasanz et al. [18, 19, 21, 22,25 ] for type strains of other representatives of the genus, such as $G$. nigrescens, G. arenarius, G. siccatus, G. saharensis, $G$. tzadiensis, and $G$. normandii, when cultivated under the same growth conditions (Table 1). Colonies were convex, nearly circular and opaque with a moist surface and an entire margin. Strain G18 ${ }^{\mathrm{T}}$ grew well on GYM Streptomyces and GEO media but did not grow on TSA, R2A, GPHF, PYGV, and Luedemann media. It grew best at $25-30^{\circ} \mathrm{C}$ but did not grow below $15^{\circ} \mathrm{C}$ or above $35^{\circ} \mathrm{C}$. Growth was observed in presence of $1 \% \mathrm{NaCl}$ and between $\mathrm{pH}$ 5.5-9.5 (optimal range $\mathrm{pH}$ 7.0-9.5). Results from phenotype microarray analysis are shown as a heatmap in the supplementary material (Figure S1) in comparison to the reference type strains of the genus Geodermatophilus. A summary of selected differential phenotypic characteristics is presented in Table 1 . In the phenotypic clustering significant support (>95\%) is obtained for G. poikilotrophi DSM $44209^{\mathrm{T}}$, G. nigrescens DSM $45408^{\mathrm{T}}$ and G. normandii DSM $45417^{\mathrm{T}}$ being most similar to each other regarding the characters present in GEN III Microplates (Suppl. Figure S2).

3.2. Chemotaxonomic Characteristics. Analysis of cell wall components revealed the presence of $D L$-diaminopimelic acid (cell wall type III), which is consistent with other species of the genus Geodermatophilus $[27,38]$. Strain $G 18^{\mathrm{T}}$ displayed primarily menaquinone $\mathrm{MK}-9\left(\mathrm{H}_{4}\right)(82.5 \%)$, in agreement with values reported for the family Geodermatophilaceae [2], but also MK-9 $\left(\mathrm{H}_{0}\right)(8.8 \%)$ and $\mathrm{MK}-9\left(\mathrm{H}_{2}\right)$ (4.8\%). Major fatty acids were iso- $\mathrm{C}_{16: 0}(24.5 \pm 0.2 \%)$, iso- $\mathrm{C}_{15: 0}(16.6 \pm$ $1.3 \%), \mathrm{C}_{17: 1} \omega 8 \mathrm{c}(13.9 \pm 0.1 \%)$ and $\mathrm{C}_{16: 1} \omega 7 \mathrm{c}(8.3 \pm 0.1 \%)$, complemented by iso- $\mathrm{C}_{16: 1} \mathrm{H}(5.6 \pm 0.9 \%)$, anteiso- $\mathrm{C}_{15: 0}$ $(4.1 \pm 0.4 \%)$, anteiso- $C_{17: 0}(4.4 \pm 0.2 \%), C_{18: 1} \omega 9 \mathrm{c}(3.6 \pm$ $0.1 \%)$ and $\mathrm{C}_{16: 0}(2.4 \pm 0.9 \%)$. The phospholipids pattern consisted of phosphatidylethanolamine (PE), phosphatidylcholine (PC), phosphatidylinositol (PI), and small amount of diphosphatidylglycerol (DPG) in accordance with profiles obtained for representatives of other Geodermatophilus species investigated in this study (Table 1). Phosphatidylglycerol was not detectable (see Supplementary Figure S3). This fact was already predictable based on phospholipids profiles displayed for other representatives of the genus such as $G$. arenarius, G. siccatus, G. tzadiensis, G. normandii, or $G$. amargosae, whose phosphatidylglycerol amounts were nearly imperceptible. Whole-cell sugar analysis revealed galactose as the diagnostic sugar [38] but also glucose and ribose. Genomic G + C content was $74.4 \mathrm{~mol} \%$.

3.3. Molecular Analysis. The almost complete (1514 bp) $16 \mathrm{~S}$ rRNA gene sequence of strain $\mathrm{G} 18^{\mathrm{T}}$ was determined. The $16 \mathrm{~S}$ rRNA sequence showed the highest degree of similarity with the type strains of G. siccatus (99.1\%), G. africanus (99.0\%), G. amargosae (98.5\%), G. normandii (98.4\%), G. obscurus (98.3\%), G. tzadiensis (98.2\%), G. nigrescens (98.1\%), G. ruber (98.0\%), and G. arenarius (98.0\%). All listed closely related type strains were placed within the same phylogenetic group by both, maximum likelihood and maximum-parsimony estimations (Figure 2). The $16 \mathrm{~S}$ rRNA gene sequences analysis thus strongly supports the assignment of strain $\mathrm{G} 18^{\mathrm{T}}$ to the genus Geodermatophilus. However, similarities in 16S rRNA gene sequence between $\mathrm{G} 18^{\mathrm{T}}$ and some closely related type strains indicated the need to prove the genomic distinctness of the type strain representing the novel species by DNADNA hybridization. Strain $\mathrm{G} 18^{\mathrm{T}}$ displayed a DNA-DNA relatedness of $35.3 \pm 1.0 \%$ with the type strain of $G$. siccatus and $28.1 \pm 2.1 \%$ with $G$. africanus. DNA-DNA hybridizations of strain $\mathrm{G}^{\mathrm{T}}{ }^{\mathrm{T}}$ with the type strains of $G$. amargosae, $G$. normandii, G. obscurus, G. tzadiensis, G. nigrescens, G. ruber, and $G$. arenarius were not conducted, according to MeierKolthoff et al. [49] that statistically confirmed that the threshold value previously established at 97\% 16S rRNA gene sequence similarity was too conservative in microbial species discrimination and determined a Actinobacteria-specific $16 \mathrm{~S}$ rRNA threshold at $99.0 \%$ with a maximun probability of error of $1.00 \%$ to get DNA-DNA hybridization values above the $70 \%$ threshold recommended by Wayne et al. [60] to confirm the species status of novel strains.

3.4. Tolerance. Gamma-radiation survival of strain $\mathrm{G} 18^{\mathrm{T}}$ (Figure 3(a)) showed not significantly different inactivation kinetic as for G. obscurus DSM $43160^{\mathrm{T}}$, which is considered 


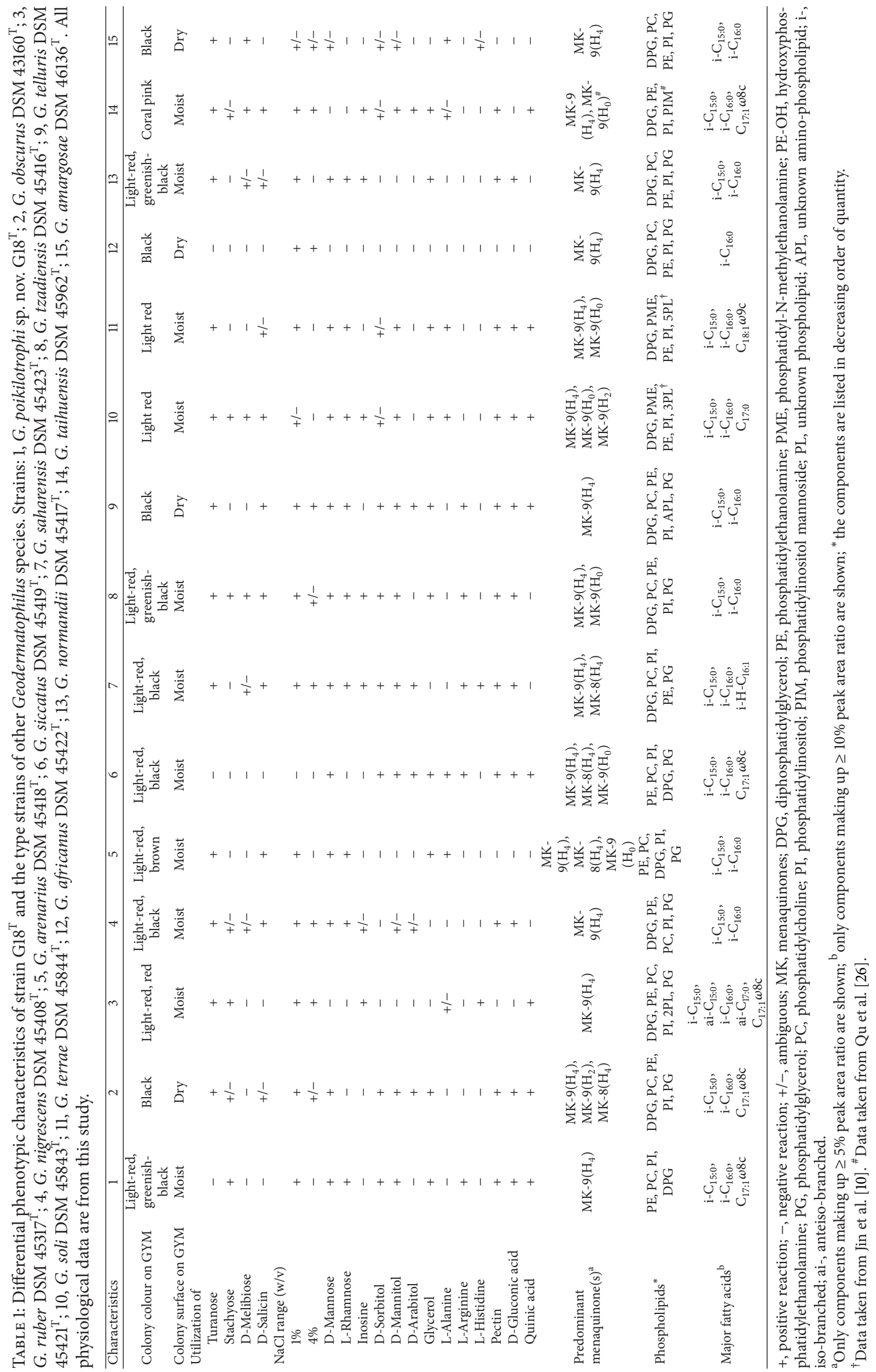




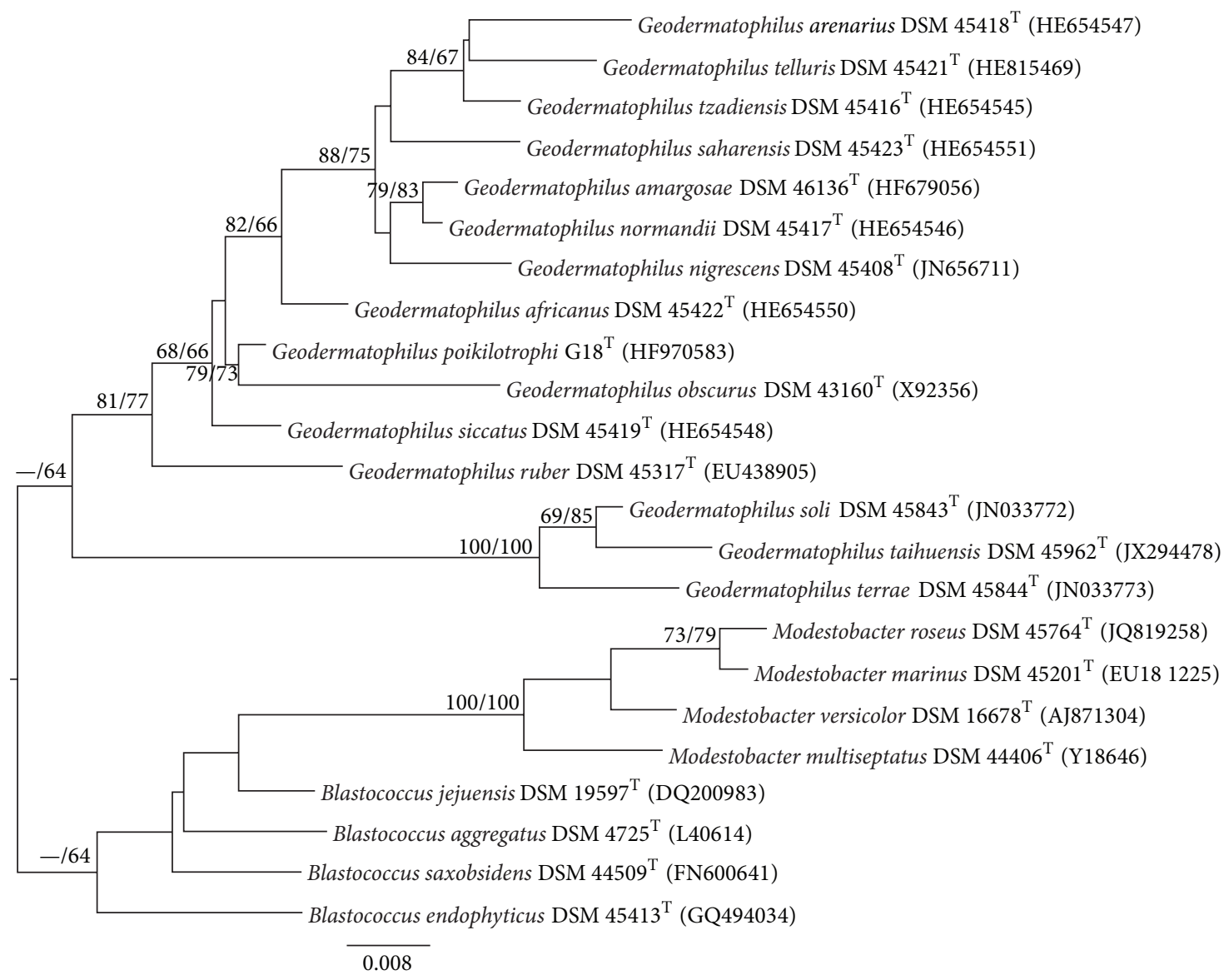

FIGURE 2: Maximum likelihood phylogenetic tree inferred from $16 \mathrm{~S}$ rRNA gene sequences, showing the phylogenetic position of strain G18 ${ }^{\mathrm{T}}$ relative to the type strains within the family cursive. The branches are scaled in terms of the expected number of substitutions per site (see size bar). Support values from maximum-likelihood (left) and maximum-parsimony (right) bootstrapping are shown above the branches if equal to or larger than $60 \%$.

as highly resistant, according to data reported by Gtari et al. [11]. Strain G18 ${ }^{\mathrm{T}}$ strains exhibited a shoulder of resistance similar to $D$. radiodurans $\mathrm{R} 1$ to approximately $5 \mathrm{KGy}$ [61], but comparatively lower than the observed one by $G$. obscurus DSM $43160^{\mathrm{T}}$. Nevertheless, LD10 of both, G18 ${ }^{\mathrm{T}}$ and G. obscurus DSM $43160^{\mathrm{T}}$, was around $9 \mathrm{KGy}$, a dose comparatively higher than the displayed one for the high radiation resistant strain $D$. radiodurans $\mathrm{R} 1$ [61], although other authors reported a LD10 around $10 \mathrm{KGy}$ by using the same strain [62]. UV-radiation survival curves revealed a similar progressive loss of viability in both strains during the first 10 min of exposure until levels below 50\%. However, the differences between the two resistant phenotypes increased along the curve, observing a significant variation on viability at $10 \%$ survival (Figure $3(\mathrm{~b})$ ). According to radiated doses, strain $\mathrm{G} 18^{\mathrm{T}}$ and $G$. obscurus DSM $43160^{\mathrm{T}}$ were capable to support the lethal effects of $6300-12600 \mathrm{~J} \cdot \mathrm{s}^{-1} \mathrm{~m}^{2}$ and $63600-31800 \mathrm{~J} \cdot \mathrm{s}^{-1} \mathrm{~m}^{2}$, respectively, sustaining a survival rate higher than 10\%. Battista [63] and Shukla et al. [62] reported LD10 values of $700-1000 \mathrm{~J} \cdot \mathrm{s}^{-1} \mathrm{~m}^{2}$ for the highly resistant $D$. radiodurans $\mathrm{R} 1$. The tolerance to $\mathrm{UV}$-radiation in the genus Geodermatophilus was already observed, in addition to G. obscurus DSM $43160^{\mathrm{T}}$, in G. tzadiensis DSM $45416^{\mathrm{T}}$ by Montero-Calasanz et al. [22]. Cultures of strain $\mathrm{G}_{1}{ }^{\mathrm{T}}$ tolerated an exposure to mitomycin of nearly 120 min showing a viability rate of $10 \%$, a value significantly higher than the one observed for the positive control (LD10 = 71 min) (Figure 3(c)). Tolerance of strain $\mathrm{G}_{18}^{\mathrm{T}}(\mathrm{LD} 10=7 \mathrm{~min})$ in comparison with the positive control G. obscurus DSM $43160^{\mathrm{T}}(\mathrm{LD} 10=8 \mathrm{~min})$ to $0.5 \%$ hydrogen peroxide along the curves did not show any significant differences (Figure 3(d)). Based on desiccation survival curves given in Figure 3(e), both strains initially exhibited a similar resistance (LD50). At the first sample point (20 days), strain $\mathrm{G} 18^{\mathrm{T}}$ showed a survival of less than $10 \%$, a value comparatively different to the results observed by G. obscurus DSM $43160^{\mathrm{T}}$, whose LD10 is reached after 38 days. However, it is worth mentioning that after 110 days a remaining bacterial population of strain $\mathrm{G} 18^{\mathrm{T}}$ was still observed. Strain $\mathrm{G} 18^{\mathrm{T}}$ demonstrated thus a high tolerance to ROS-generating stresses gamma- and UVradiation, mitomycin $\mathrm{C}$, hydrogen peroxide, and desiccation comparable to the positive control G. obscurus DSM $43160^{\mathrm{T}}$ and, in general terms, to DNA damaging-resistant D. radiodurans $\mathrm{R} 1$. This correlative tolerance between ROSgenerating stresses was already widely described $[11,62]$ and support the hypothesis of efficient and common cellular 


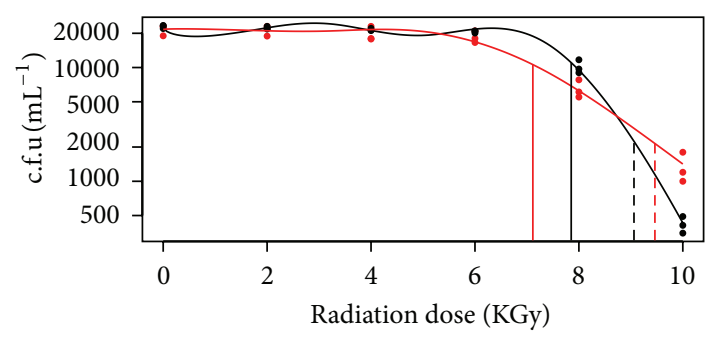

Lethal dose(s)
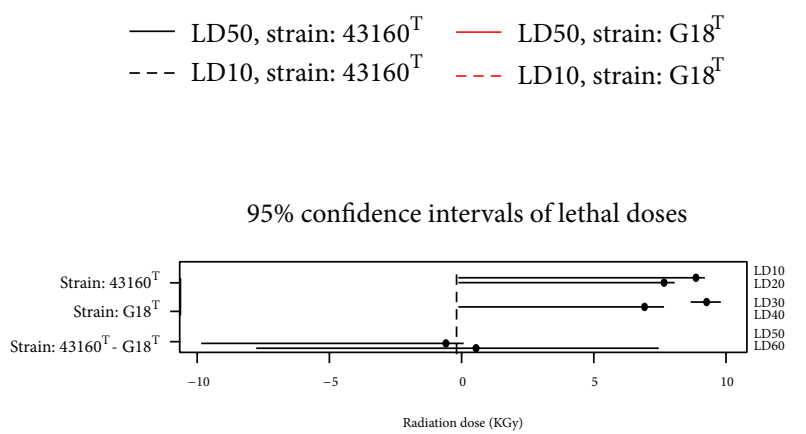

(a)

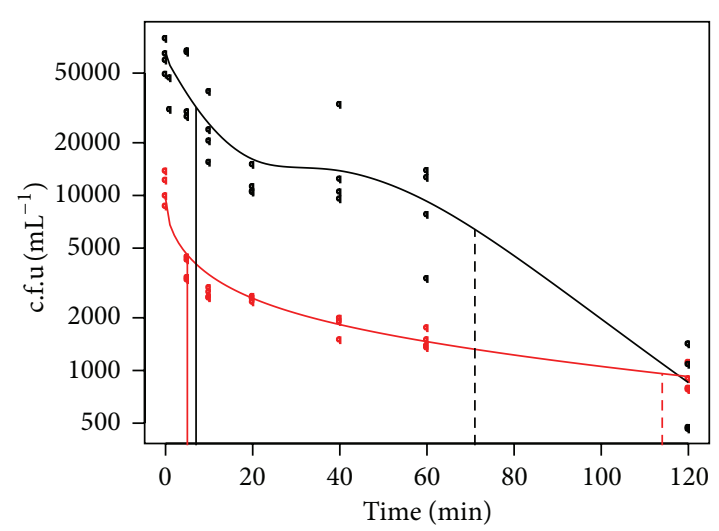

Lethal dose(s)
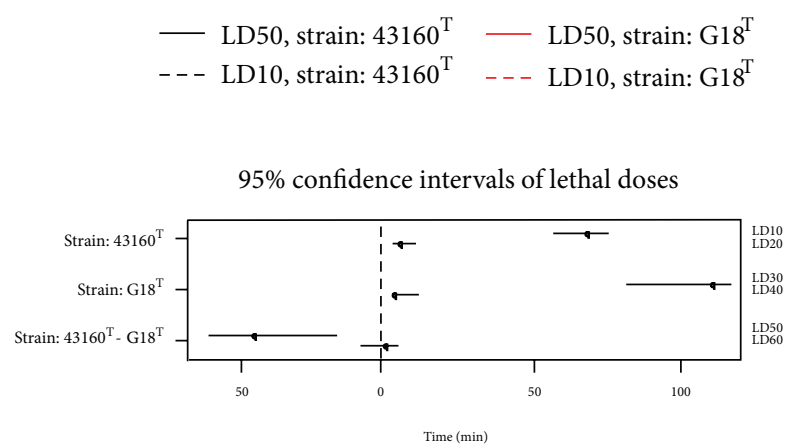

(c)

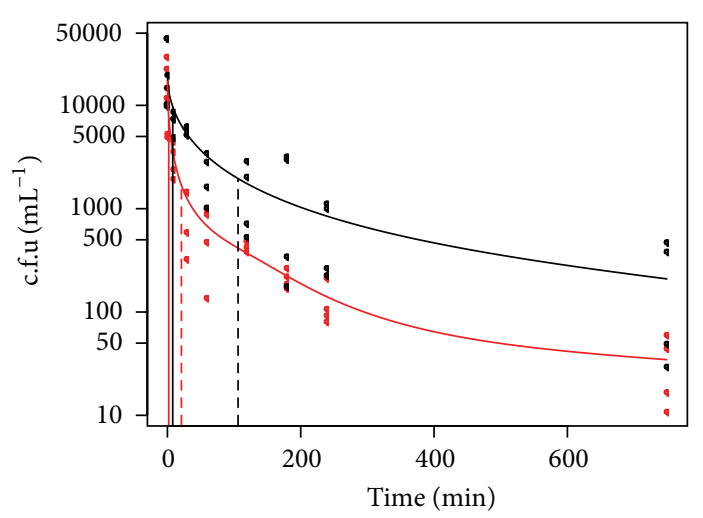

Lethal dose(s)

— LD50, strain: $43160^{\mathrm{T}}$ - LD50, strain: G18 ${ }^{\mathrm{T}}$

_- - LD10, strain: $43160^{\mathrm{T}} \quad$ - - - LD10, strain: $\mathrm{G} 18^{\mathrm{T}}$

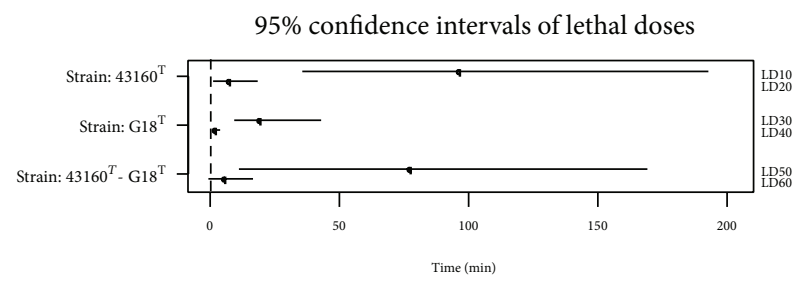

(b)

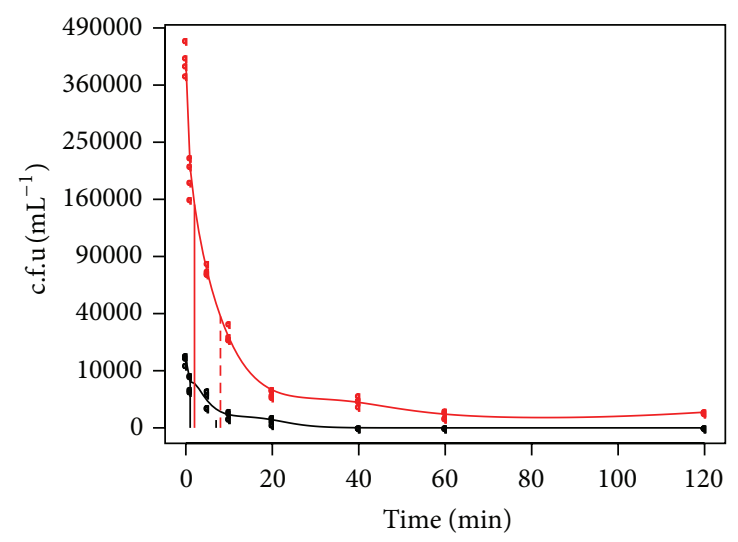

Lethal dose(s)

$\begin{array}{lll}\text { — LD50, strain: } 43160^{\mathrm{T}} & \text { - LD50, strain: G18 } \\ \text { - - LD10, strain: } 43160^{\mathrm{T}} & \text { - - LD10, strain: } \mathrm{G} 18^{\mathrm{T}}\end{array}$

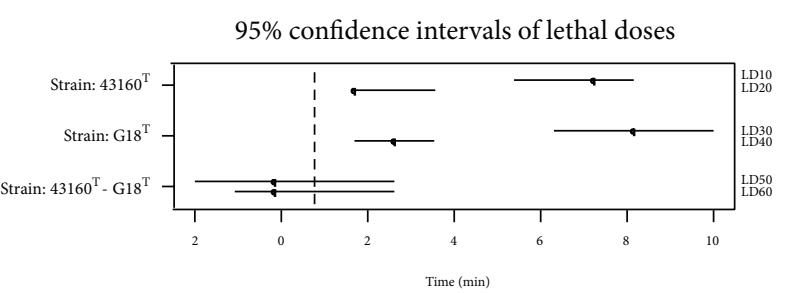

(d)

Figure 3: Continued. 

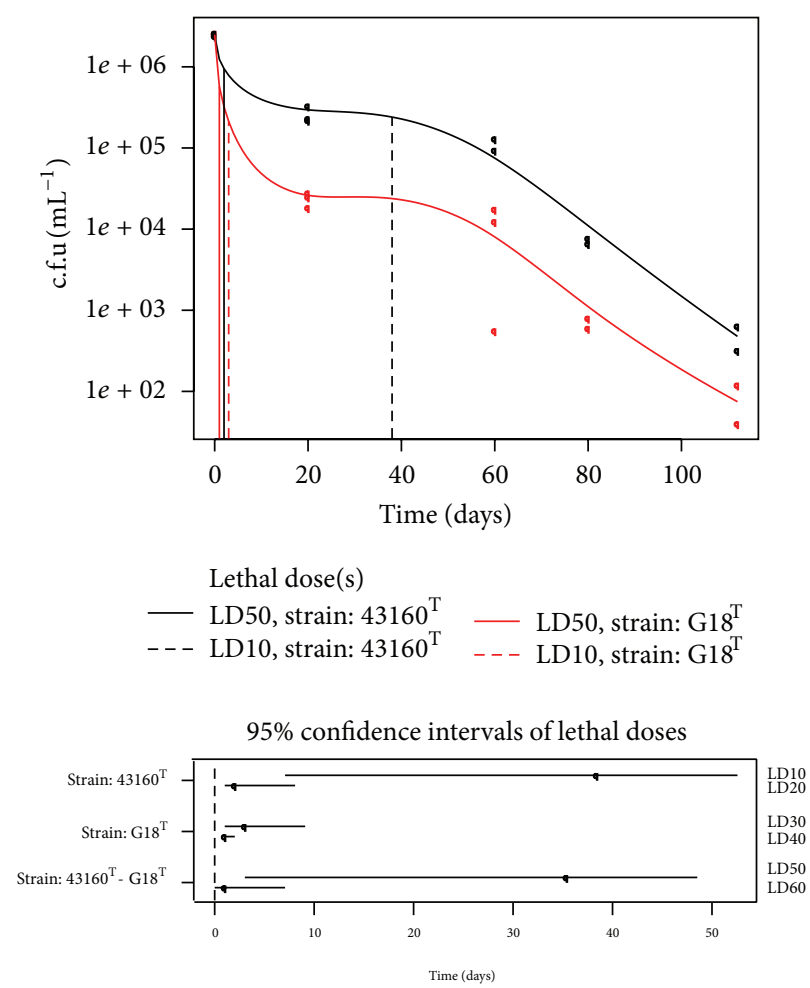

(e)

FIGURE 3: Estimation of survival following exposure to gamma-radiation (a), UV-radiation (b), mitomycin C (c), hydrogen peroxide (d), and desiccation (e) for strain $\mathrm{G}_{18}^{\mathrm{T}}$ and G. obscurus DSM $43160^{\mathrm{T}}$ as positive control. The mean c.f.u. $\mathrm{mL}^{-1}$ per strain is given together with the LD50 and LD10 values in the upper panel of each figure; $y$-axis is on a logarithmic scale ((a)-(c), (e)), or on a square root scale (d). The lower panel depicts LD10 and LD50 values per strain and the differences between strains together with confidence intervals. Confidence intervals that do not contain zero (dashed vertical line) indicate significant differences to zero; in case of strain differences this indicates significant differences between strains.

DNA repair mechanisms. Strain $\mathrm{G} 18^{\mathrm{T}}$ showed the highest tolerance to $\mathrm{AsO}_{4}{ }^{3-}(\mathrm{MIC}=8.0 \mathrm{mM})$ followed by $\mathrm{Pb}^{2+}$ $(\mathrm{MIC}=4.0 \mathrm{mM}), \mathrm{CrO}_{4}^{2-}(\mathrm{MIC}=4.0 \mathrm{mM})$ and $\mathrm{Ag}^{1+}(\mathrm{MIC}$ $=1.0 \mathrm{mM})$. Whereas the growth of G. obscurus DSM $43160^{\mathrm{T}}$ was mainly inhibited by concentrations below $1.0 \mathrm{mM}$, except $\mathrm{AsO}_{4}{ }^{3-}$ whose sensitivity was 10 times higher $(\mathrm{MIC}=$ $80.0 \mathrm{mM}$ ) than the one observed for strain $\mathrm{G}^{\mathrm{T}}{ }^{\mathrm{T}}$ (Table 2). It has been widely described that the heavy metals/metalloids exposure also produces ROS generation [64]. In this study, a correspondence with other ROS-generating stresses was not observed, in agreement with data reported by Gtari et al. [11] for G. obscurus DSM $43160^{\mathrm{T}}$, but also for Modestobacter multiseptatus BC501 and Blastococcus saxobsidens DD2, suggesting the presence of alternative mechanisms to counteract the heavy metals/metalloids stress, such as transport outside the cells [65], adsorption on exocellular structures such as melanin [66], or enzymatic reduction to less toxic forms [67, 68]. Although it is noteworthy that toxicity levels of lead and copper in G. obscurus DSM $43160^{\mathrm{T}}$ by comparison with the results displayed by Gtari et al. [11] were much different from each other. These divergences in the levels of tolerance might be due to the differences in the media compositions [69]. In addition, it was confirmed that neither phosphate buffer nor carbon source concentration present in GYM Streptomyces medium caused an overestimated metals tolerance of strains, justified by the different tolerance range found in both strains and its mostly correlation with the results described by Gtari et al. [11].

Apart from the phylogenetic analysis based on 16S rRNA gene sequences, several phenotypic features support the distinctiveness of strain $\mathrm{G}_{1} 8^{\mathrm{T}}$ from representatives of all other Geodermatophilus species (Table 1). Based on the phenotypic and genotypic data presented, we propose that strain $\mathrm{G} 18^{\mathrm{T}}$ represents a novel species within the genus Geodermatophilus, with the name Geodermatophilus poikilotrophi sp. nov.

Description of Geodermatophilus poikilotrophi sp. nov.. Geodermatophilus poikilotrophi (poi.kil.o.troph'i N. L. fem. gen. n. poikilotrophi referring to a bacterium that can tolerate diverse environmental stresses).

Colonies are greenish-black-coloured, circular, and convex with a moist surface. Cells are Gram-reaction-positive, catalase positive, and oxidase negative. No diffusible pigments are produced on any of the tested media. Utilizes dextrin, $\mathrm{D}$-maltose, $\mathrm{D}$-trehalose, $\mathrm{D}$-cellobiose, sucrose, stachyose, $\mathrm{D}$-glucose, $\mathrm{D}$-mannose, $\mathrm{D}$-fructose, $\mathrm{D}$-galactose, L-rhamnose, D-sorbitol, D-mannnitol, myo-inositol, glycerol, L-arginine, pectin, D-gluconic acid, quinic acid, methyl 
TABLE 2: Minimum inhibitory concentration of seven heavy metals and metalloids for strain G18 ${ }^{\mathrm{T}}$ and G. obscurus DSM $43160^{\mathrm{T}}$.

\begin{tabular}{|c|c|c|c|c|c|c|c|}
\hline \multirow{2}{*}{ Strain } & \multicolumn{7}{|c|}{ MIC $(\mathrm{mM})$ of } \\
\hline & $\mathrm{AgNO}_{3}$ & $\mathrm{CuCl}_{2}$ & $\mathrm{CoCl}_{2}$ & $\mathrm{NiCl}_{2}$ & $\mathrm{~K}_{2} \mathrm{CrO}_{4}$ & $\mathrm{~Pb}\left(\mathrm{NO}_{3}\right)_{2}$ & $\mathrm{NaHAsO}_{4}$ \\
\hline $\mathrm{G} 18^{\mathrm{T}}$ & 1.0 & 0.1 & 0.3 & 0.5 & 4.0 & 4.0 & 8.0 \\
\hline DSM $43160^{\mathrm{T}}$ & 0.3 & 0.1 & 0.3 & 0.3 & 1.0 & 1.0 & 80.0 \\
\hline
\end{tabular}

pyruvate, D-lactic acid methyl ester, $\alpha$-ketoglutaric acid, D-malic acid, bromosuccinic acid, potassium tellurite, $\Upsilon$ amino-N-butyric acid, acetoacetic acid, propionic acid, acetic acid, as sole carbon source for energy and growth, but not turanose, D-raffinose, D-melibiose, $\beta$-methyl-Dglucoside, D-salicin, $N$-acetyl-D-glucosamine, $N$-acetyl-Dgalactosamine, $\mathrm{N}$-acetylneuraminic acid, 3-O-methyl-Dglucose, D-fucose, inosine, sodium lactate, D- and Lserine, D-arabitol, D-glucose-6-phosphate, D-aspartic acid, glycyl-L-proline, L-alanine, L-glutamic acid, L-histidine, Lpyroglutamic acid, L-galactonic acid- $\gamma$-lactone, glucuronamide, mucic acid, D-saccharic acid, $p$-hydroxyphenylacetic acid, citric acid, $\gamma$-amino-n-butyric acid, and butyric acid. Acid is produced from L-arginine and $\Upsilon$-amino-N-butyric acid and can be used as a sole nitrogen source but not $N$-acetyl-D-glucosamine, $N$-acetyl-D-galactosamine, $N$ acetyl-neuraminic acid, D- and L-serine, D-aspartic acid, glycyl-L-proline, L-alanine, L-histidine, L-glutamic acid, L-histidine, L-pyroglutamic acid, glucuronamide, and $\gamma$ amino-n-butyric acid. Positive for aesculin degradation. Negative for reduction of nitrate, denitrification, indole production and gelatin degradation. Tests for alkaline phosphatase, esterase lipase (C8), esterase (C4), leucine arylamidase and $\alpha$-glucosidase are positive, but those for urease, $\beta$-glucosidase, acid phosphatase, valine arylamidase, Naphthol-AS-BI-phosphohydrolase, lipase (C14), cystine arylamidase, trypsin, $\alpha$-chymotrypsin, $\alpha$ - and $\beta$ galactosidase, $\beta$-glucuronidase, $\mathrm{N}$-acetyl- $\beta$-glucosamidase, $\alpha$-mannosidase and $\alpha$-fucosidase are negative. Cell growth ranges from 15 to $35^{\circ} \mathrm{C}$ and from $\mathrm{pH} 5.5$ to 9.5 . It is tolerant to gamma- and UV-radiation, mitomycin $\mathrm{C}$, hydrogen peroxide, desiccation and heavy metals/metalloids $\mathrm{AsO}_{4}{ }^{3-}$, $\mathrm{Pb}^{2+}, \mathrm{CrO}_{4}{ }^{2-}$ and $\mathrm{Ag}^{1+}$. The peptidoglycan in the cell wall contains meso-diaminopimelic acid as diamino acid, with galactose as the diagnostic sugar. The predominant menaquinone is MK-9 $\left(\mathrm{H}_{4}\right)$. The main polar lipids are phosphatidylethanolamine, phosphatidylcholine, phosphatidylinositol, and small amount of diphosphatidylglycerol. Cellular fatty acids consist mainly of iso- $\mathrm{C}_{16: 0}$, iso- $\mathrm{C}_{15: 0}, \mathrm{C}_{17: 1} \omega 8 \mathrm{c}$, and $\mathrm{C}_{16: 1} \omega 7 \mathrm{c}$. The type strain has a genomic DNA G $+\mathrm{C}$ content of $74.4 \mathrm{~mol} \%$. The INSDC accession number for the 16S rRNA gene sequences of the type strain $\mathrm{G} 18^{\mathrm{T}}\left(=\mathrm{DSM} 44209^{\mathrm{T}}=\right.$ CCUG $63018^{\mathrm{T}}$ ) is HF970583.

\section{Conflict of Interests}

The authors declare that there is no conflict of interests regarding the publication of this paper.

\section{Acknowledgments}

The authors would like to acknowledge the help of Bettina Sträubler and Birgit Grün for DNA-DNA hybridization analyses, Gabi Pötter for assistance with chemotaxonomy, Brian J. Tindall (all at DSMZ, Germany) for his guidance in the chemotaxonomic analyses, and Haitham Sghaier (CNSTN, Tunisia) for providing access to the gamma irradiation facility. Maria del Carmen Montero-Calasanz is the recipient of a postdoctoral contract from the European Social Fund Operational Programme (2007-2013) for Andalusia and also recipient of a DSMZ postdoctoral fellowship (2013-2015).

\section{References}

[1] P. Normand, S. Orso, B. Cournoyer et al., "Molecular phylogeny of the genus Frankia and related genera and emendation of the family Frankiaceae," International Journal of Systematic Bacteriology, vol. 46, no. 1, pp. 1-9, 1996.

[2] P. Normand, "Geodermatophilaceae fam. nov., a formal description," International Journal of Systematic and Evolutionary Microbiology, vol. 56, part 10, pp. 2277-2278, 2006.

[3] G. M. Luedemann, "Geodermatophilus, a new genus of the Dermatophilaceae (Actinomycetales)," Journal of Bacteriology, vol. 96, no. 5, pp. 1848-1858, 1968.

[4] V. B. D. Skerman, V. McGowan, and P. H. A. Sneath, "Approved lists of bacterial names," International Journal of Systematic Bacteriology, vol. 30, no. 1, pp. 225-420, 1980.

[5] M. D. Montero-Calasanz, M. Göker, G. Pötter et al., "Geodermatophilus africanus sp. nov., a halotolerant actinomycete isolated from Saharan desert sand," Antonie van Leeuwenhoek, vol. 104, no. 2, pp. 207-216, 2013.

[6] C. Urzì, L. Brusetti, P. Salamone, C. Sorlini, E. Stackebrandt, and D. Daffonchio, "Biodiversity of Geodermatophilaceae isolated from altered stones and monuments in the Mediterranean basin," Environmental Microbiology, vol. 3, no. 7, pp. 471-479, 2001.

[7] M. Eppard, W. E. Krumbein, C. Koch, E. Rhiel, J. T. Staley, and E. Stackebrandt, "Morphological, physiological, and molecular characterization of actinomycetes isolated from dry soil, rocks, and monument surfaces," Archives of Microbiology, vol. 166, no. 1, pp. 12-22, 1996.

[8] A. A. Gorbushina, "Life on the rocks," Environmental Microbiology, vol. 9, no. 7, pp. 1613-1631, 2007.

[9] Y. Q. Zhang, J. Chen, H. Y. Liu, Y. Q. Zhang, W. J. Li, and L.-Y. Yu, "Geodermatophilus ruber sp. nov., isolated from rhizosphere soil of a medicinal plant," International Journal of Systematic and Evolutionary Microbiology, vol. 61, part 1, pp. 190-193, 2011.

[10] L. Jin, H.-G. Lee, H.-S. Kim, C.-Y. Ahn, and H.-M. Oh, "Geodermatophilus soli sp. nov. and Geodermatophilus terrae sp. nov., two actinobacteria isolated from grass soil," International 
Journal of Systematic and Evolutionary Microbiology, vol. 63, part 7, pp. 2625-2629, 2013.

[11] M. Gtari, I. Essoussi, R. Maaoui et al., "Contrasted resistance of stone-dwelling Geodermatophilaceae species to stresses known to give rise to reactive oxygen species," FEMS Microbiology Ecology, vol. 80, no. 3, pp. 566-577, 2012.

[12] V. Mattimore and J. R. Battista, "Radioresistance of Deinococcus radiodurans: functions necessary to survive ionizing radiation are also necessary to survive prolonged desiccation," Journal of Bacteriology, vol. 178, no. 3, pp. 633-637, 1996.

[13] K. W. Minton, "DNA repair in the extremely radioresistant bacterium Deinococcus radiodurans," Molecular Microbiology, vol. 13, no. 1, pp. 9-15, 1994.

[14] K. W. Minton, "Repair of ionizing-radiation damage in the radiation resistant bacterium Deinococcus radiodurans," Mutation Research: DNA Repair, vol. 363, no. 1, pp. 1-7, 1996.

[15] F. A. Rainey, K. Ray, M. Ferreira et al., "Extensive diversity of ionizing-radiation-resistant bacteria recovered from Sonoran Desert soil and description of nine new species of the genus Deinococcus obtained from a single soil sample," Applied Environmmental Microbiology, vol. 71, no. 9, pp. 5225-5235, 2005.

[16] A. Giongo, J. Favet, A. Lapanje et al., "Microbial hitchhikers on intercontinental dust: high-throughput sequencing to catalogue microbes in small sand samples," Aerobiologia, vol. 29, no. 1, pp. 71-84, 2013.

[17] G. X. Nie, H. Ming, S. Li et al., “Geodermatophilus nigrescens sp. nov., isolated from a dry-hot valley," Antonie van Leeuwenhoek, vol. 101, no. 4, pp. 811-817, 2012.

[18] M. C. Montero-Calasanz, M. Göker, G. Pötter et al., “Geodermatophilus arenarius sp. nov., a xerophilic actinomycete isolated from Saharan desert sand in Chad," Extremophiles, vol. 16, no. 6, pp. 903-909, 2012.

[19] M. del Carmen Montero-Calasanz, M. Göker, M. Rohde et al., "Geodermatophilus siccatus sp. nov., isolated from arid sand of the Saharan desert in Chad," Antonie van Leeuwenhoek, vol. 103, no. 3, pp. 449-456, 2013.

[20] J. Euzéby, "List of new names and new combinations previously effectively, but not validly, published," International Journal of Systematic and Evolutionary Microbiology, vol. 63, part 5, pp. 1577-1580, 2013.

[21] M. C. Montero-Calasanz, M. Göker, G. Pötter et al., “Geodermatophilus saharensis sp. nov., isolated from sand of the Saharan desert in Chad," Archives of Microbiology, vol. 195, no. 3, pp. 153159, 2013.

[22] M. D. C. Montero-Calasanz, M. Göker, W. J. Broughton et al., "Geodermatophilus tzadiensis sp. nov., a UV radiation-resistant bacterium isolated from sand of the Saharan desert," Systematic and Applied Microbiology, vol. 36, no. 3, pp. 177-182, 2013.

[23] A. Oren and G. M. Garrity, "List of new names and new combinations previously effectively, but not validly, published," International Journal of Systematic and Evolutionary Microbiology, vol. 63, pp. 3931-3934.

[24] M. D. C. Montero-Calasanz, M. Göker, G. Pötter et al., “Geodermatophilus telluris sp. nov., an actinomycete isolated from Saharan desert sand," International Journal of Systematic and Evolutionary Microbiology, vol. 63, part 6, pp. 2254-2259, 2013.

[25] M. C. Montero-Calasanz, M. Göker, G. Pötter et al., "Geodermatophilus normandii sp. nov., isolated from Saharan desert sand," International Journal of Systematic and Evolutionary Microbiology, vol. 63, part 9, pp. 3437-3443, 2013.
[26] J.-H. Qu, M. Hui, J.-Y. Qu et al., “Geodermatophilus taihuensis sp. nov., isolated from $\mathrm{t}$ he interfacial sediment of a eutrophic lake," International Journal of Systematic and Evolutionary Microbiology, vol. 63, pp. 4108-4112, 2013.

[27] M. C. Montero-Calasanz, M. Göker, M. Rohde et al., "Description of Geodermatophilus amargosae sp. nov., to accommodate the not validly named Geodermatophilus obscurus subsp. amargosae (Luedemann,1968)," Current Microbiology, vol. 68, no. 3, pp. 365-371, 2014.

[28] A. Oren and G. M. Garrity, "Validation List no. 158. List of new names and new combinations previously effectively, but not validly, published," International Journal of Systematic and Evolutionary Microbiology, vol. 64, part 5, pp. 1455-1458, 2014.

[29] N. Ivanova, J. Sikorski, M. Jando et al., "Complete genome sequence of Geodermatophilus obscurus type strain (g-20 T)," Standards in Genomic Sciences, vol. 2, no. 2, pp. 158-167, 2010.

[30] E. E. Ishiguro and D. W. Fletcher, "Characterization of Geodermatophilus strains isolated from high altitude Mount Everest soils," Mikrobiologika, vol. 12, pp. 99-108, 1975.

[31] P. Normand and D. R. Benson, "Genus I. Geodermatophilus Luedemann 1968. 1994," in Bergey's Manual of Systematic Bacteriology: The Actinobacteria, vol. 5, part 1, pp. 528-530, Springer, New York, NY, USA, 2nd edition, 2012.

[32] M. J. Pelczar Jr., Manual of Microbiological Methods, McGrawHill, New York, NY, USA, 1957.

[33] T. Gregersen, "Rapid method for distinction of gram negative from gram positive bacteria," European Journal of Applied Microbiology, vol. 5, no. 2, pp. 123-127, 1978.

[34] E. B. Shirling and D. Gottlieb, "Methods for characterization of Streptomyces species," International Journal of Systematic Bacteriology, vol. 16, pp. 313-340, 1966.

[35] L. A. I. Vaas, J. Sikorski, V. Michael, M. Göker, and H.-P. Klenk, "Visualization and curve-parameter estimation strategies for efficient exploration of phenotype microarray kinetics," PLoS ONE, vol. 7, no. 4, Article ID e34846, 2012.

[36] L. A. I. Vaas, J. Sikorski, B. Hofner et al., "Opm: an R package for analysing OmniLog (R) phenotype microarray data," Bioinformatics, vol. 29, no. 14, pp. 1823-1824, 2013.

[37] R. Suzuki and H. Shimodaira, "pvclust: hierarchical clustering with $\mathrm{p}$-values via multiscale bootstrap resampling," $\mathrm{R}$ package version 01.2-2, http://cran.r-project.org/web/packages/ pvclust/index.html.

[38] M. P. Lechevalier and H. A. Lechevalier, "Chemical composition as a criterion in the classification of aerobic actinomycetes," International Journal of Systematic Bectoriology, vol. 20, pp. 435443, 1970.

[39] J. L. Staneck and G. D. Roberts, "Simplified approach to identification of aerobic actinomycetes by thin layer chromatography," Journal of Applied Microbiology, vol. 28, no. 2, pp. 226-231, 1974.

[40] D. E. Minnikin, A. G. O’Donnell, M. Goodfellow et al., "An integrated procedure for the extraction of bacterial isoprenoid quinones and polar lipids," Journal of Microbiological Methods, vol. 2, no. 5, pp. 233-241, 1984.

[41] R. M. Kroppenstedt and M. Goodfellow, "The family Thermomonosporaceae: Actinocorallia, Actinomadura, Spirillispora and Thermomonospora," in The Prokaryotes, vol. 3 of Archaea and Bacteria: Firmicutes, Actinomycetes, pp. 682-724, Springer, New York, NY, USA, 3rd edition, 2006.

[42] B. J. Tindall, "A comparative study of the lipid composition of Halobacterium saccharovorum from various sources," Systematic and Applied Microbiology, vol. 13, no. 2, pp. 128-130, 1990. 
[43] M. D. Collins, T. Pirouz, M. Goodfellow, and D. E. Minnikin, "Distribution of menaquinones in actinomycetes and corynebacteria," Journal of General Microbiology, vol. 100, no. 2, pp. 221-230, 1977.

[44] R. M. Kroppenstedt, "Separation of bacterial menaquinones by HPLC using reverse phase (RP18) and a silver loaded ion exchanger," Journal of Liquid Chromatography, vol. 5, no. 12, pp. 2359-2387, 1982.

[45] M. Sasser, "Identification of bacteria by gas chromatography of cellular fatty acids," USFCC Newsl, vol. 20, p. 16, 1990.

[46] K. H. Schleifer and O. Kandler, "Peptidoglycan types of bacterial cell walls and their taxonomic implications," Bacteriological Reviews, vol. 36, no. 4, pp. 407-477, 1972.

[47] M. Mesbah, U. Premachandran, and W. B. Whitman, "Precise measurement of the $\mathrm{G}+\mathrm{C}$ content of deoxyribonucleic acid by high-performance liquid chromatography," International Journal of Systematic Bacteriology, vol. 39, no. 2, pp. 159-167, 1989.

[48] F. A. Rainey, N. Ward-Rainey, R. M. Kroppenstedt, and E. Stackebrandt, "The genus Nocardiopsis represents a phylogenetically coherent taxon and a distinct actinomycete lineage: proposal of Nocardiopsaceae fam. nov.", International Journal of Systematic Bacteriology, vol. 46, no. 4, pp. 1088-1092, 1996.

[49] J. P. Meier-Kolthoff, M. Göker, C. Spröer, and H. Klenk, "When should a DDH experiment be mandatory in microbial taxonomy?" Archives of Microbiology, vol. 195, no. 6, pp. 413-418, 2013.

[50] P. Cashion, M. A. Holder Franklin, J. McCully, and M. Franklin, "A rapid method for the base ratio determination of bacterial DNA," Analytical Biochemistry, vol. 81, no. 2, pp. 461-466, 1977.

[51] J. de Ley, H. Cattoir, and A. Reynaerts, "The quantitative measurement of DNA hybridization from renaturation rates," European Journal of Biochemistry, vol.12, no. 1, pp. 133-142, 1970.

[52] V. A. R. Huss, H. Festl, and K. H. Schleifer, "Studies on the spectrophotometric determination of DNA hybridization from renaturation rates," Systematic and Applied Microbiology, vol. 4, no. 2, pp. 184-192, 1983.

[53] E. E. Ishiguro and R. S. Wolfe, "Induction of morphogenesis in Geodermatophilus by inorganic cations and by organic nitrogenous cations," Journal of Bacteriology, vol. 117, no. 1, pp. 189-195, 1974.

[54] J. W. Richards, G. D. Krumholz, M. S. Chval, and L. S. Tisa, "Heavy metal resistance patterns of Frankia strains," Applied and Environmental Microbiology, vol. 68, no. 2, pp. 923-927, 2002.

[55] P. McCullagh and J. A. Nelder, Generalized Linear Models, Chapman \& Hall, London, UK, 2nd edition, 1989.

[56] P. H. C. Eilers and B. D. Marx, "Flexible smoothing with $B$ splines and penalties," Statistical Science, vol. 11, no. 2, pp. 89121, 1996.

[57] S. N. Wood, Generalized Additive Models: An Introduction with $R$, CRC press, 2006.

[58] R Core Team, A Language and Environment for Statistical Computing, R Foundation for Statistical Computing, Vienna, Austria, 2014, http://www.R-project.org/.

[59] B. Hofner, "lethal: Compute lethal doses (LD) with confidence intervals," $\mathrm{R}$ package, http://r-forge.r-project.org/projects/lethal/.

[60] L. G. Wayne, D. J. Brenner, R. R. Colwell et al., "Report of the Ad Hoc committee on reconciliation of approaches to bacterial systematics," International Journal of Systematic Bacteriology, vol. 37, no. 4, pp. 463-464, 1987.
[61] J. R. Battista, A. M. Earl, and M. J. Park, "Why is Deinococcus radiodurans so resistant to ionizing radiation?" Trends in Microbiology, vol. 7, no. 9, pp. 362-365, 1999.

[62] M. Shukla, R. Chaturvedi, D. Tamhane et al., "Multiplestress tolerance of ionizing radiation-resistant bacterial isolates obtained from various habitats: correlation between stresses," Current Microbiology, vol. 54, no. 2, pp. 142-148, 2007.

[63] J. R. Battista, "Against all odds: the survival strategies of Deinococcus radiodurans," Annual Review of Microbiology, vol. 51, pp. 203-224, 1997.

[64] S. J. Stohs and D. Bagchi, "Review article oxidative mechanisms in the toxicity of metals ions," Free Radical Biology and Medicine, vol. 18, no. 2, pp. 321-336, 1995.

[65] D. H. Nies, "The cobalt, zinc, and cadmium efflux system CzcABC from Alcaligenes eutrophus functions as a cationproton antiporter in Escherichia coli," Journal of Bacteriology, vol. 177, no. 10, pp. 2707-2712, 1995.

[66] R. V. Fogarty and J. M. Tobin, "Fungal melanins and their interactions with metals," Enzyme and Microbial Technology, vol. 19, no. 4, pp. 311-317, 1996.

[67] A. M. Spain, A. D. Peacock, J. D. Istok et al., "Identification and isolation of a Castellaniella species important during biostimulation of an acidic nitrate- and uranium-contaminated aquifer," Applied and Environmental Microbiology, vol. 73, no. 15, pp. 4892-4904, 2007.

[68] A. C. Poopal and R. S. Laxman, "Studies on biological reduction of chromate by Streptomyces griseus," Journal of Hazardous Materials, vol. 169, no. 1-3, pp. 539-545, 2009.

[69] I. V. N. Rathnayake, M. Megharaj, G. S. R. Krishnamurti, N. S. Bolan, and R. Naidu, "Heavy metal toxicity to bacteria: are the existing growth media accurate enough to determine heavy metal toxicity?" Chemosphere, vol. 90, no. 3, pp. 1195-1200, 2013. 

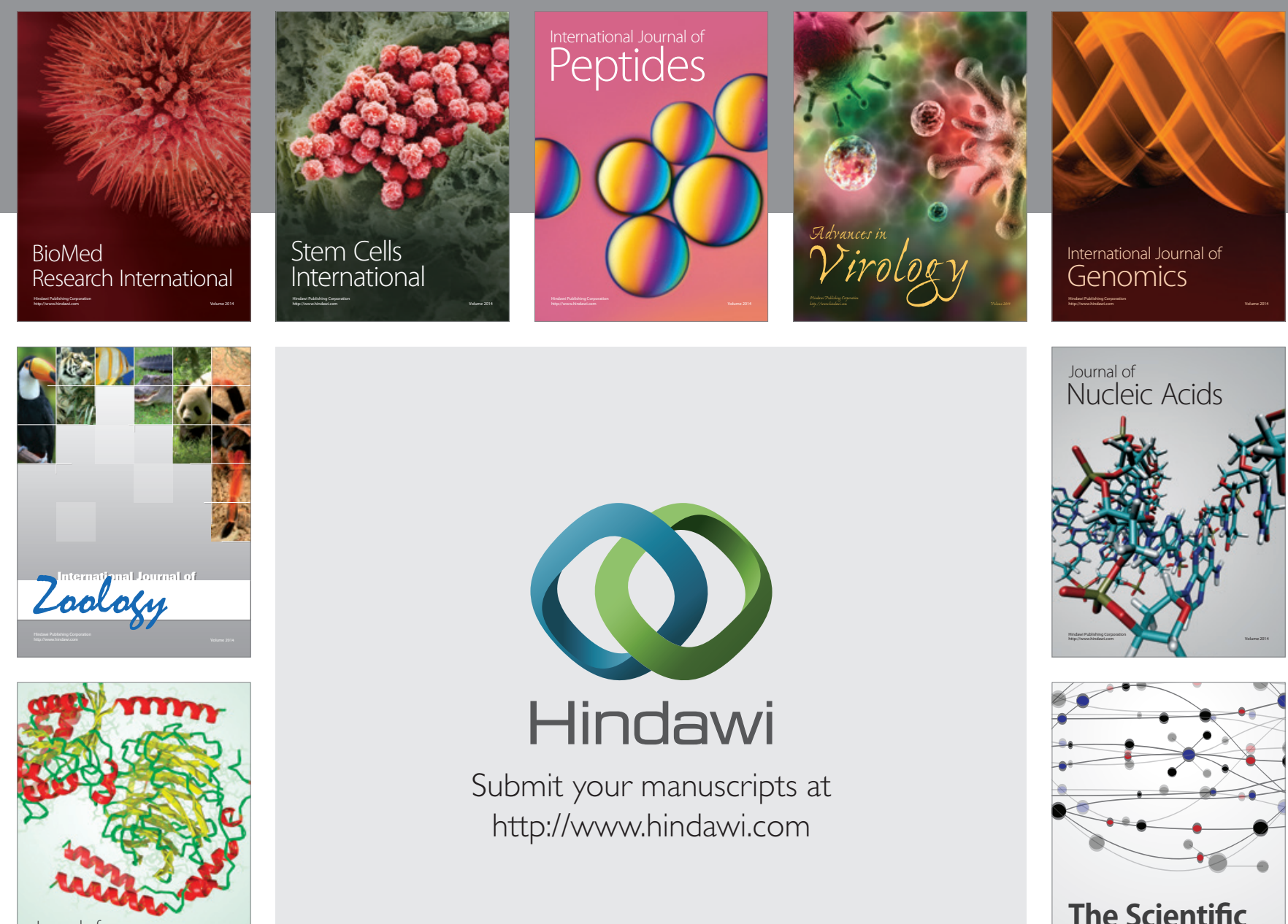

Submit your manuscripts at

http://www.hindawi.com

Journal of
Signal Transduction
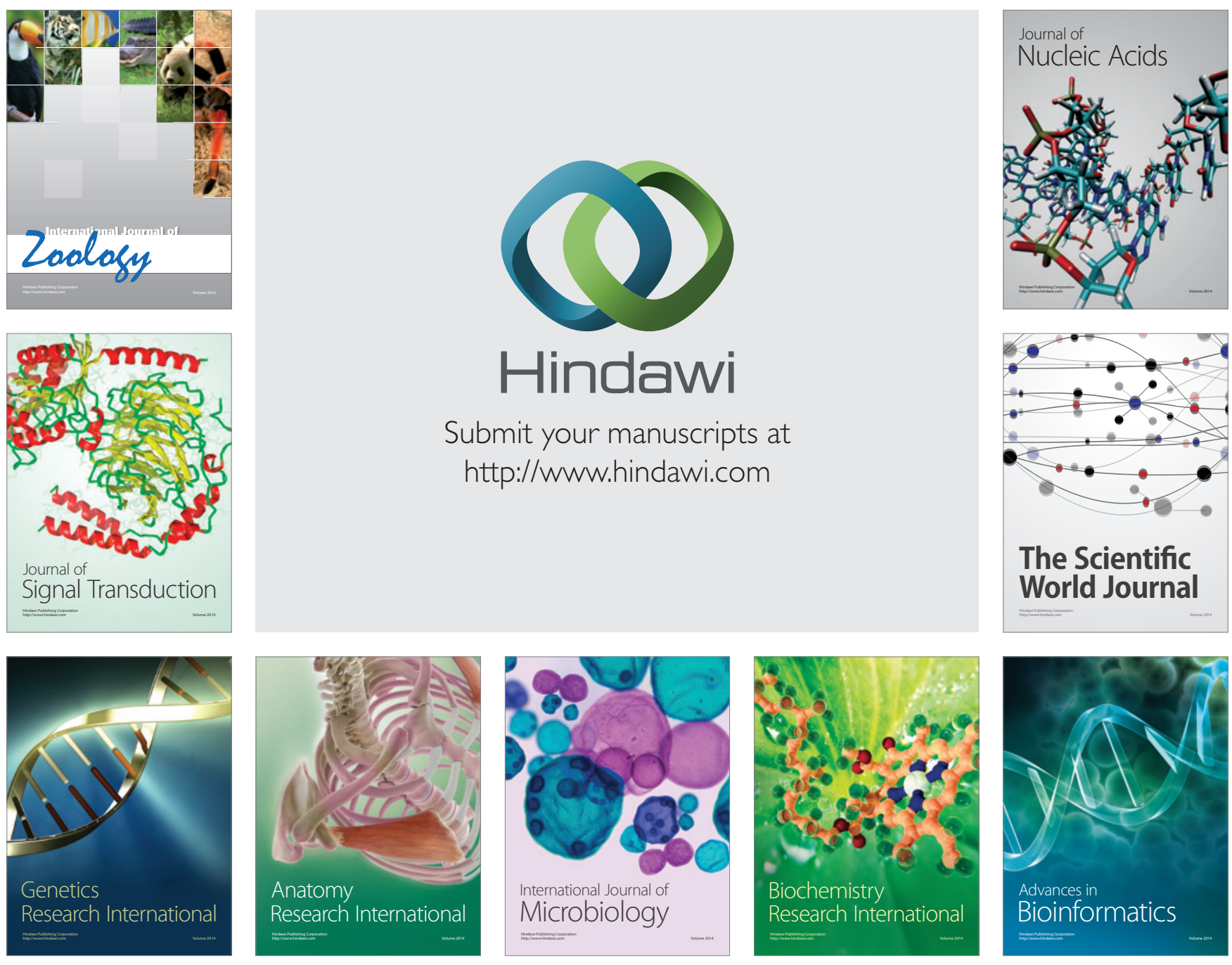

The Scientific World Journal
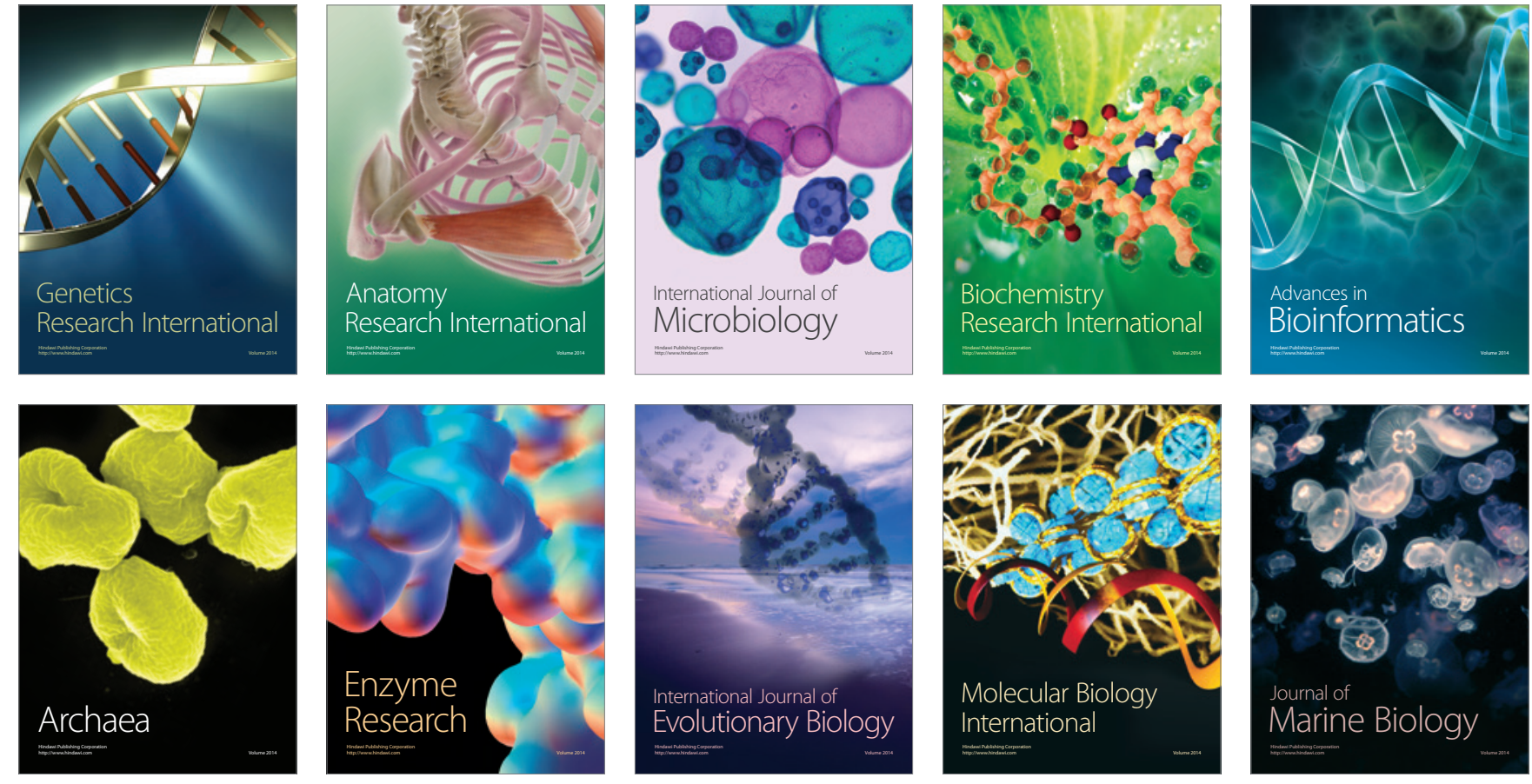